\title{
LICITAÇÕES SUSTENTÁVEIS NA JUSTIÇA DO TRABALHO
}

\section{JOSÉ OrCÉLIO dO NASCIMENTO}

Doutorando em Contabilidade, Universidade de São Paulo - USP-RP, Brasil.

jorcelio@uol.com.br

\section{Leila Alves Machado de Souza}

Especialista em controladoria pública, Fundação Escola e Comércio Álvares Penteado - FECAP, Brasil. leilaalves41@gmail.com

\section{Marcus Vinicius MoReIRA ZitTEI}

Doutor em Ciências Contábeis e Administração, Universidade Regional de Blumenau - FURB, Brasil.

Professor do Mestrado Profissional em Administração em Governança Corporativa, Faculdades Metropolitanas Unidas - MPA-GC/FMU, Brasil.

marcuszittei@zittei.com.br

\section{LEONARDO FABRIS LUGOBONI}

Doutor em Administração, Universidade de São Paulo -USP, Brasil.

Professor de Graduação, Fundação Escola e Comércio Álvares Penteado - FECAP, Brasil.

leonardo.lugoboni@fecap.br

\section{Resumo}

Licitações sustentáveis têm por objetivo integrar soluções ambientais e sociais nos estágios dos processos de compra e contratação do poder público com o propósito de reduzir impactos à saúde humana e ao meio ambiente. Este estudo analisou a atuação da Justiça do Trabalho no tocante à compatibilização das legislações que regulamentam essas licitações verificando os critérios de sustentabilidade utilizados nesta Justiça Especializada. A metodologia utilizada foi qualitativa, descritiva, foram coletados dados dos Relatórios de Gestão de 2012 disponibilizados no site do Tribunal de Contas da União. Conclui-se que apesar dos esforços da Administração Pública em implementar critérios socioambientais nas compras e contratações públicas, a maioria das instituições em questão necessitam adotar ações mais eficazes, eficientes e efetivas para colocar em prática os critérios de sustentabilidade em seus processos licitatórios de forma permanente. Palavras-chave: sustentabilidade, licitação positiva, gestão pública. 


\title{
SUSTAINABLE BIDDINGS ON LABOR COURT
}

\begin{abstract}
Sustainable bids seek to integrate environmental and social solutions at the stages of public power's purchase and hiring processes aiming to reduce impacts to human health and the environment. This study analyzed the Labor Court's performance related to the legislation's compatibility that regulates these bids, verifying the sustainability criteria used in this Specialized Court. The used methodology was qualitative and descriptive. Data from the Management Reports for 2012 were collected from the Tribunal de Contas da União's website. It was concluded that despite Public Administration's efforts to implement social and environmental criteria in public purchase and hiring, most institutions need to take more effective, efficient and effective actions to put sustainability criteria into practice in their bidding processes on a permanent basis.
\end{abstract}

Keywords: sustainability. positive bid. public management.

\section{LICITACIONES SUSTENTABLES EN LA JUSTICIA DEL TRABAJO}

\begin{abstract}
Resumen
Las licitaciones sustentables tienen como objetivo integrar soluciones ambientales y sociales en las etapas de los procesos de compra y contratación del poder público con el propósito de reducir impactos a la salud humana y al medio ambiente. Este estudio analizó la actuación de la Justicia de Trabajo en cuanto a la compatibilización de las legislaciones que regulan esas licitaciones verificando los criterios de sustentabilidad utilizados en esta Justicia Especializada. La metodología utilizada fue cualitativa, descriptiva, fueron recolectados datos de los Informes de Gestión del 2012, disponibles en la página del Tribunal de Contas da União. Se concluye que a pesar de los esfuerzos de la Administración Pública en implementar criterios socioambientales en las compras y contrataciones públicas, la mayoría de las instituciones en cuestión necesitan adoptar acciones más eficaces, eficientes y efectivas para poner en práctica los criterios de sustentabilidad en sus procesos licitatorios de forma permanente.
\end{abstract}

Palabras clave: Sostenibilidad, licitaciones positivas, gestión pública. 


\section{INTRODUÇÃO}

Nas últimas décadas, o conceito de sustentabilidade tem ganhado notoriedade global, principalmente após a realização das Conferências das Nações Unidas sobre o Meio Ambiente, onde foram debatidas questões como "qualidade de vida" e "esgotamento dos recursos naturais", na tentativa de propor soluções que reduzam os impactos negativos gerados, em parte, pelo desenvolvimento tecnológico e econômico sobre o meio ambiente.

Há pouco mais de 25 anos, desde o Relatório de Brundtland elaborado pela Comissão Mundial sobre o Meio Ambiente e Desenvolvimento da Organização das Nações Unidas - ONU (1987), também conhecido como "Nosso Futuro Comum", introduziu o conceito de desenvolvimento sustentável como sendo "o desenvolvimento que encontra as necessidades atuais sem comprometer a habilidade das futuras gerações de atender as suas próprias necessidades (ONU, 1987).

Pode-se notar que diversas Constituições Nacionais em diversos países já tentaram equacionar, da melhor forma possivel, políticas voltadas à sustentabilidade, de modo a reconhecer o direito de todos a um meio ambiente ecologicamente equilibrado, garantindo dessa forma, a disponibilidade dos recursos naturais (Machado, 2011).

A aplicação de algumas mudanças na forma de aquisição pelo setor público possibilita que os "processos licitatórios sustentáveis garantam o meio ambiente ecologicamente equilibrado, de modo a não gerar impactos ambientais com externalidades negativas" (Costa, Diniz, Cunha \& Pires, 2016).

0 presente estudo pretende discutir um desses mecanismos constitucionalmente legitimado, chamado de licitação sustentável, compra "verde", ecoaquisição ou licitação positiva, e que segundo Meneguzzi (2011), a licitação sustentável seria também uma solução para integrar considerações ambientais e sociais em todos os estágios do processo da compra e contratação dos agentes públicos (de governo) com o objetivo de reduzir impactos à saúde humana, ao meio ambiente e aos direitos humanos.

No Brasil, o diploma legal que dispõe especificamente sobre licitações públicas é a Lei nº 8.666/1993, que teve o caput do artigo $3^{\circ}$ alterado pela Medida Provisória $n^{\circ}$ 495/2010, (posteriormente transformada na Lei $n^{0} 12.349 / 2010$ ), para incluir como finalidade precípua 0 termo "desenvolvimento nacional sustentável", garantindo dessa forma a conciliação entre os princípios da isonomia dos licitantes e o atendimento aos interesses públicos.

Ressalta-se que a Constituição Federal congrega vários princípios ambientais que perpassam o texto constitucional como um todo (Bertogna, 2011). Faz-se aqui menção ao artigo 225 que confere ao meio ambiente o status de patrimônio público de uso comum e que, portanto, deve ser preservado para as gerações posteriores:

\footnotetext{
Art. 225. Todos têm direito ao meio ambiente ecologicamente equilibrado, bem de uso comum do povo e essencial à sadia qualidade de vida, impondo-se ao Poder Público e à coletividade o dever de defendê-lo e preservá-lo para as presentes e futuras gerações.
}

Assim, a preocupação com o meio ambiente ensejou o surgimento de uma consciência "verde" e a partir dela, a criação de diversos dispositivos legais que serviram de reforço ao preconizado na Carta Magna.

O objetivo geral desta pesquisa é analisar a estratégia de atuação dos Tribunais Regionais do Trabalho no tocante à compatibilização das legislações que regulamentam as licitações públicas e a adoção de critérios de sustentabilidade para suas compras e contratações.

OS, Organizações e Sustentabilidade, 7(2), p. 99-113, Londrina, PR, jul./dez. 2019.

ISSN 2318-9223, http://www.uel.br/revistas/uel/index.php/ros/issue/view/1607/showToc 
Por meio das compras públicas, o governo tem o poder de promover um enorme estímulo para atividades inovadoras. Na Europa, os contratos públicos têm estado no centro das recentes discussões sobre a inovação política a respeito de contratações sustentáveis (Brammer \& Walker, 2011).

Em virtude de ser grande consumidora e usuária de recursos naturais, a Administração Pública pode assumir um papel estratégico na promoção e indicação de novos padrões de produção e consumo.

O entendimento acima é compartilhado por Bliacheris (2011): Neste sentido, as licitações sustentáveis incorporam claros elementos de incentivo, ao abrir um mercado significativo às empresas que produzem de um modo mais limpo e de menor impacto ambiental. O Estado passa a ter um papel indutor, ao criar mercado para tais produtos, possibilitando sua produção em escala maior, o que levaria à diminuição dos seus preços e facilitando o seu acesso por particulares. Porém, há outra dimensão na interferência estatal na alteração dos padrões de produção e consumo, que são as regras estabelecendo as exigências ambientais para os agentes econômicos produtores de bens e serviços. Neste sentido, há clara ação de comando e controle que levará à introdução de critérios obrigatórios de sustentabilidade ambiental nas contratações públicas bem como na atividade econômica privada.

A Lei $n^{\circ}$ 12.349, em 15 de dezembro de 2010, a qual alterou o art. $3^{\circ}$ da Lei $n^{\circ} 8.666 / 93$, introduziu 0 desenvolvimento nacional sustentável como uma das finalidades do procedimento licitatório.

Em relação à licitação sustentável, é possivel dizer que a sua prática é muito recente e que os critérios de sustentabilidade estão sendo introduzidos de maneira gradativa às compras governamentais.

De acordo com Valente (2011), no que se refere à realização de licitações, a Constituição Federal estabelece que exista igualdade de condições a todos os concorrentes e veda a existência de exigências que venham comprometer o caráter isonômico da licitação.

O Guia de Inclusão de Critérios de Sustentabilidade nas contratações da Justiça do Trabalho, do Conselho Superior da Justiça do Trabalho - CSJT (Brasil, 2011) corrobora com as ideias expostas acima:

Os Tribunais Regionais do Trabalho procuram implementar planos de ações estratégicas que agreguem critérios de sustentabilidade aos processos licitatórios de compras e contratação de bens e serviços, procurando equilibrar-se no tripé sustentável do ambientalmente correto, economicamente viável e socialmente justo.

\section{REFERENCIAL TEÓRICO}

Quando a Administração Pública necessita comprar bens, alugar imóveis e contratar serviços ou realizar obras terão que fazê-lo através da licitação, conforme disposto no artigo $2^{\circ}$ da Lei $n^{\circ}$ 8.666/1993.

Segundo Meirelles (2003), licitação é o procedimento administrativo mediante o qual a Administração Pública seleciona a proposta mais vantajosa para o contrato de seu interesse. Como procedimento, desenvolve-se através de uma sucessão ordenada de atos vinculantes para a Administração e para os licitantes, o que propicia igual oportunidade a todos os interessados e atua como fator de eficiência e moralidade nos negócios administrativos.

Assim sendo, a licitação consiste em um procedimento administrativo no qual a Administração Pública, através de condições pré-estabelecidas em edital, convoca empresas a apresentarem propostas, para no final escolher como vencedora aquela que oferecer bens e/ou serviços que atendam ao princípio da vantajosidade econômica.

A Lei $n^{0} 12.349$, em 15 de dezembro de 2010, a qual alterou 0 art. $3^{\circ}$ da Lei $n^{0} 8.666 / 93$, introduziu 0 desenvolvimento nacional sustentável como uma das finalidades do procedimento licitatório.

OS, Organizações e Sustentabilidade, 7(2), p. 99-113, Londrina, PR, jul./dez. 2019.

ISSN 2318-9223, http://www.uel.br/revistas/uel/index.php/ros/issue/view/1607/showToc 
A Constituição Federal de 1988 foi inovadora no Brasil ao estabelecer, pela primeira vez, o conceito de "meio ambiente" em seu bojo, denominando-o como "bem de uso comum do povo", mostrando a necessidade da implementação de políticas públicas que visassem proteger este bem.

Visto que, além da inserção do termo "meio ambiente" na Carta Maior, também os compromissos que o Governo brasileiro assumiu com as comunidades internacionais em prol da sustentabilidade global (Barki, 2011), fez com que se tornasse imprescindivel a adoção de políticas nacionais introdutórias dos critérios sustentáveis às aquisições e às contratações públicas.

Assim sendo, surgem os primeiros conceitos de licitações sustentáveis, a exemplo de Bliacheris (2011), as licitações sustentáveis são uma das políticas públicas para a preservação do meio ambiente. A introdução de critérios de sustentabilidade ambiental nas contratações públicas representa um novo modo de agir do Estado que responde a um anseio social de viver com menor impacto no meio ambiente.

Cabe ressaltar, que o entendimento disposto no Programa de Compras Sustentáveis dos Covernos Locais pela Sustentabilidade - ICLEI (Brasil, 2007) coaduna-se com Bliacheris (2011) ao dispor que uma compra é sustentável quando o comprador considera a necessidade real de efetuar a compra, as circunstâncias em que o produto visado foi gerado, levando em conta os materiais e as condições de trabalho de quem o gerou, uma avaliação de como o produto se comportará em sua vida útil e a sua disposição final.

A partir daí, vê-se que as chamadas licitações sustentáveis ou "compras ambientalmente amigáveis" abrangiam uma série de processos interligados que visavam, a partir da utilização do poder de compra do Estado, exigir atitudes sustentáveis das empresas que teriam de adequar-se às boas práticas ambientais para vender seus produtos ao setor público.

Da mesma forma, as contratações públicas sustentáveis podem ser definidas como compras que consideram critérios de sustentabilidade enquanto fundamentais para o desenvolvimento econômico e social e que conservem o meio ambiente.

A proposta mais vantajosa, nem sempre pode ser interpretada como a proposta de menor preço, pois carece que sejam verificadas as vantagens ambientais dos produtos ou serviços a serem adquiridos.

\section{LICITAÇÕES SUSTENTÁVEIS E AS NORMAS REGULADORAS}

A Constituição Federal de 1988 no inciso VI do art. 170 e no caput do art. 225 estabelecem princípios em defesa ao meio ambiente como bem público a ser preservado a todas as gerações, no entanto, alguns anos antes se encontrava em vigência a Lei n ${ }^{0}$ 6.938/1981 que dispõe sobre a Política Nacional do Meio Ambiente.

Outro instrumento de relevância ao processo de amadurecimento de ideais sustentáveis foi a Agenda 21 elaborada a final da Conferência Rio-92, realizada no Rio de Janeiro em 1992, destacando, especialmente, o capítulo 4 que ao tratar da mudança dos padrões de consumo, pregou o desenvolvimento de políticas nacionais que estimulassem mudanças nos padrões insustentáveis de consumo.

Cabe ressaltar a importância da Agenda Ambiental da Administração Pública - A3P, por tratar-se de um projeto cujo objetivo principal foi o de estimular os gestores públicos a adotarem e incorporarem atitudes voltadas à gestão ambiental em suas tarefas rotineiras através do uso racional dos bens públicos e do manejo adequado dos resíduos.

OS, Organizações e Sustentabilidade, 7(2), p. 99-113, Londrina, PR, jul./dez. 2019.

ISSN 2318-9223, http://www.uel.br/revistas/uel/index.php/ros/issue/view/1607/showToc 
A A3P foi desenvolvida pelo Ministério do Meio Ambiente em 1999, tornando-se o marco introdutório da consciência ambiental no âmbito da Administração Pública, visto que, incorporou as boas práticas sustentáveis, sem apresentar natureza impositiva ou normativa.

Revela-se também importante a Lei $n^{0} 10.257 / 2001$ que, ao regulamentar os artigos constitucionais 182 e 183, estabeleceram "diretrizes gerais da política urbana" (Guia TST, 2012), como a adoção de medidas que observassem a compatibilização da expansão urbana com os limites da sustentabilidade ambiental, social e econômica do Município e do Território sob sua área de influência.

A partir de 2010, a Secretaria de Logística e Tecnologia da Informação do Ministério do Planejamento, Orçamento e Gestão - SLTI/MPOC publica a Instrução Normativa $n^{0}$ 01/2010, a qual dispõe "sobre os critérios de sustentabilidade ambiental na aquisição de bens, contratação de serviços ou obras pela Administração Pública Federal direta, autárquica e fundacional", impondo medidas efetivas para adoção de critérios sustentáveis em todas as fases da licitação, além de demonstrar preocupação em assegurar tratamento isonômico entre os licitantes e compatibilizar a seleção da proposta mais vantajosa à Administração Pública com as atitudes socioambientais.

Ainda em 2010, uma série de acontecimentos denotou ações voltadas à sustentabilidade, como o lançamento do Portal de Contratações Sustentáveis do Governo Federal e a definição de especificações técnicas para aquisições dos computadores "verdes" pelo MPOC em abril, fazendo deste ano uma referência no tocante à consolidação das compras sustentáveis na Administração Pública Federal.

Por sua vez, a Lei n 12.187/2009, que instituiu a Política Nacional sobre a Mudança do Clima, procura relacionar as alterações climáticas aos problemas ambientais provocados, sobretudo, pelo modelo de produção instaurado a partir da revolução industrial, baseado nos combustíveis fósseis, na exploração desmedida dos recursos naturais, bem como no descuido quanto aos resíduos gerados pelos processos produtivos (Ferreira, 2011).

Através desta relação, surge a definição da matéria tratada no inciso XII do artigo $6^{\circ}$ da Lei $n^{0}$ 12.187/2009, ou seja, a preocupação em estabelecer critérios de preferências nas licitações por produtos que propiciem "maior economia de energia, água e outros recursos naturais e redução da emissão de gases de efeito estufa e de resíduos".

A Lei $n^{0}$ 12.305/2010, ao dispor sobre a Política Nacional de Resíduos Sólidos, veio reforçar o dispositivo legal anterior. A medida fortaleceu os conceitos inaugurados pela legislação $n^{0}$ 12.187/2009 e demonstrou preocupação com o último elo de ciclo de vida dos produtos.

Finalmente, acontece a celebração do termo de Acordo de Cooperação Técnica $n^{0}$ 51/2010 entre 0 CNJ e CSJT, que faz a Justiça do Trabalho aderir, oficialmente, ao Processo Judicial eletrônico - PJe, com intuito de reduzir gastos com papel, insumos e transportes e diminuir o tempo de tramitação processual.

Com relação a esse reforço, Ferreira (2011) explica que se percebe claramente a complementaridade entre os dois, pois a reciclagem e o consumo social e ambientalmente sustentáveis (Lei de Resíduos Sólidos) são dois pilares primordiais para o enfretamento das mudanças climáticas e exemplos fundamentais de medidas para uma maior economia de energia, água e outros recursos naturais, bem como para a redução da emissão de resíduos, conforme determinado pela Lei de Mudança do Clima.

Destaca-se, ainda, a importância da referida Lei ao abordar temas que são necessários à preservação do meio ambiente para as presentes e futuras gerações, nos termos preconizados pelo artigo $225 \mathrm{da}$ Carta Maior, tal como reciclagem de resíduos e coleta seletiva.

OS, Organizações e Sustentabilidade, 7(2), p. 99-113, Londrina, PR, jul./dez. 2019. 
Em março de 2011, o CSJT e os 24 Tribunais Regionais do Trabalho assinaram um novo Acordo de Cooperação Técnica $n^{0}$ 01/2011, no qual coloca os servidores à disposição do projeto de desenvolvimento e aprendizagem do PJe.

Nessa mesma linha, a Lei $n^{0}$ 12.462/2011, conhecida como Regime Diferenciado de Contratações Públicas - RDC institui um regime diferenciado de licitação e contrato para atender obras de infraestrutura para as cidades que serão sedes dos jogos da Copa do Mundo de futebol em 2014 e dos Jogos Olímpicos e Paraolímpicos em 2016, trazendo em seu bojo instruções relativas à necessidade de assegurar que as inovações tecnológicas produzam reduzidos impactos ambientais.

Mais uma vez, de forma inovadora, o governo federal inaugurou o Decreto $n^{0} 7.746 / 2012$ no qual definiu que "a administração pública federal direta, autárquica e fundacional e as empresas estatais dependentes poderão adquirir bens e contratar serviços e obras considerando critérios e práticas de sustentabilidade objetivamente definidos no instrumento convocatório".

Cumpre ressaltar que o referido marco legal criou a Comissão Interministerial de Sustentabilidade na Administração Pública visando estabelecer outros meios de veicular critérios e práticas de sustentabilidade nas contratações, levando em conta a redução do impacto no meio ambiente de um modo geral.

Recentemente, através do Termo de Adesão do Ministério do Meio Ambiente e Agenda Ambiental na Administração Pública - MMA-A3P/2013 serão integrados esforços no desenvolvimento de projetos destinados à implantação de programas ambientais no âmbito das instituiç̧ões públicas federais, visando à inserção da variável socioambiental no cotidiano e na qualidade de vida do ambiente de trabalho.

Finalmente, interessante ressaltar que o Tribunal de Contas da União - TCU, órgão de controle externo que antes apresentava postura resistente no tocante às compras "verdes" por considerá-las supérfluas e com altos custos, atualmente, em vários julgados enaltece a prática das licitações sustentáveis.

Desse modo, após breve análise dos diplomas legais no âmbito federal, podemos perfilhar a perspectiva de Betiol et al. (2012) ao inferir que as ecoaquisições possuem amparo legal convincente, visto que, até mesmo o TCU requisita em seus relatórios de gestão a adoção, por parte das Unidades Jurisdicionadas, de práticas de licitação sustentável, sendo objeto de cobrança e punição o não cumprimento das mesmas.

\section{NORMAS DO TRIBUNAL REGIONAL DO TRABALHO DA 2ª REGIÃO A RESPEITO DAS LICITAÇÕES E CONTRATAÇÕES SUSTENTÁVEIS}

Os Tribunais Regionais do Trabalho do País adequaram-se às normas vigentes através de seus normativos internos.

Os TRT's em atendimento ao preconizado na Recomendação $n^{0}$ 11/2007 do Conselho Nacional de Justiça - CNJ, que propõe a adoção de políticas públicas que visem à formação e recuperação de um ambiente ecologicamente equilibrado, e na Recomendação $n^{0}$ 103/2012 do Conselho Superior da Justiça do Trabalho - CSJT, a qual "aprova o Guia Prático para a inclusão de critérios de sustentabilidade nas contratações de bens e serviços no âmbito da Justiça do Trabalho de primeiro e segundo graus", movem-se no sentido de estabelecer, em seus normativos internos, legislação alinhada às boas práticas de sustentabilidade.

Cumpre transcrever que o CNJ é uma instituição pública que visa aperfeiçoar o trabalho do sistema judiciário brasileiro, enquanto o CSIT é um ente que exerce a supervisão administrativa, orçamentária, financeira e patrimonial, com a finalidade de promover a integração e o desenvolvimento da Justiça do Trabalho de primeiro e segundo graus.

OS, Organizações e Sustentabilidade, 7(2), p. 99-113, Londrina, PR, jul./dez. 2019.

ISSN 2318-9223, http://www.uel.br/revistas/uel/index.php/ros/issue/view/1607/showToc 
Posto isto, observa-se que o Tribunal Regional do Trabalho da $2^{\mathrm{a}}$ Região - TRT $2^{\mathrm{a}}$ com o escopo de alinhar-se à Recomendação CNJ $n^{0}$ 11/2007, publica a Portaria do Gabinete da Presidência - GP $n^{0}$ 17/2008 na qual foi constituída a Comissão Permanente de Cestão Socioambiental, que dentre outras finalidades tem como compromisso "desenvolver projetos e ações de combate ao desperdício e de minimização dos impactos ambientais".

Do mesmo modo, segue-se a publicação da Portaria CP $n^{0}$ 19/2010, desta vez objetivando cumprir metas prioritárias estabelecidas pelo CSIT para o ano de 2010, a qual conclama os setores administrativos e judiciais a imprimir peças processuais com a utilização da frente e verso do papel para reduzir o consumo do mesmo.

Dando continuidade ao plano de ação estratégica, ainda em 2010, o Tribunal implementou mais cinco programas de sustentabilidade, que são: adoção da coleta seletiva; destinação correta e reciclagem dos resíduos perigosos; substituição dos copos plásticos por canecas, a realização de licitações sustentáveis; e a conscientização dos magistrados e servidores para o uso racional de recursos de água, luz e papel.

Importante destacar ainda, a publicação do Ato GP $n^{0}$ 07/2011, da Presidência deste Regional, que "institui e regulamenta a Política Ambiental no âmbito do Tribunal Regional do Trabalho da $2^{a}$ Região", o qual determina a adoção de "critérios de sustentabilidade nos processos licitatórios no âmbito do Tribunal, considerando os impactos e os benefícios nas dimensões econômica, ambiental e social", bem como na Resolução n 103/2012 do Conselho Superior da Justiça do Trabalho.

Faz-se necessário apontar que, por meio da Resolução CSJT n 103/2010 foi aprovado o Guia Prático para inclusão de critérios de sustentabilidade que deverão ser observados na contratação de obras e serviços e na aquisição de bens no âmbito da Justiça do Trabalho de primeiro e segundo grau, considerando também o estabelecimento de diferentes práticas sustentáveis, além das previstas no Guia, dependendo das peculiaridades regionais.

\section{METODOLOGIA}

Quanto à abordagem, o trabalho em questão utilizou o enfoque qualitativo, descritivo e documental. Martins e Theóphilo (2009) afirmam que a pesquisa qualitativa se preocupa com a descrição de um modo geral, procurando compreender e interpretar os fatos, ao invés de utilizar medições.

Na opinião de Sampieri, Collado e Luccio (2006), os métodos descritivos medem, avaliam ou coletam dados sobre diversos aspectos, dimensões ou componentes do fenômeno a ser pesquisado. Do ponto de vista científico, descrever é coletar dados (para os pesquisadores quantitativos, medir; para os qualitativos, coletar informações.

Segundo Martins e Theóphilo (2009), para se compor uma plataforma teórica de qualquer estratégia de investigação são conduzidas pesquisas bibliográficas - levantamento de referências expostas em meios escritos ou de outros tipos. A pesquisa documental se assemelha à pesquisa bibliográfica, todavia não levanta material editado - livros, periódicos etc. -, mas busca material que não foi editado, como cartas, memorandos, correspondências de outros tipos, avisos, agendas, propostas, relatórios, estudos, avaliações etc. Pesquisas documentais são frequentes nos estudos orientados por estratégias participativas: Estudo de Caso, Pesquisa-Ação etc.

A metodologia utilizada para realizar a presente pesquisa revestiu-se de uma investigação bibliográfica, caracterizando dessa forma o cunho científico de uma abordagem qualitativa, onde se fez necessário para este fim o emprego de metodologia que buscasse elementos na legislação vigente, em bibliografias disponiveis acerca do tema, houve a necessidade de incorrer a buscas em sítios da Internet de órgãos governamentais como Tribunal de Contas da União - TCU, Supremo Tribunal Federal, Tribunais Regionais do Trabalho, além de órgãos internacionais como Organização

OS, Organizações e Sustentabilidade, 7(2), p. 99-113, Londrina, PR, jul./dez. 2019.

ISSN 2318-9223, http://www.uel.br/revistas/uel/index.php/ros/issue/view/1607/showToc 
das Nações Unidas - ONU e Programa de Compras Sustentáveis dos Governos Locais pela Sustentabilidade - ICLEI e outros catalogados no referencial bibliográfico.

Foram realizadas pesquisas com base nos Relatórios de Cestão (2012) dos Tribunais Regionais do Trabalho, que estão disponíveis no site do Tribunal de Contas da União. Esta pesquisa se limitou ao período de 2012 em razão de ser o primeiro ano da implantação desta legislação na Justiça do Trabalho a escolha da Justiça do trabalho para esta pesquisa deve-se ao valor expressivo de seu orçamento que para o ano de 2012 foi de $\mathrm{R} \$$ 14.702.410.054,29 (Quatorze bilhões, setecentos e dois milhões, quatrocentos e dez mil, cinquenta e quatro reais e vinte e nove centavos). Esses relatórios apresentam no item 9, em observação a Parte A do Anexo II da Decisão Normativa-TCU n0 108/2010 e Portaria TCU n 123/2011, quadro comparativo referente à gestão do uso dos recursos renováveis e sustentabilidade ambiental, onde a Unidade Jurisdicionada deve fazer sua autoavaliação com níveis de notas de 1 a 5, que serão detalhadas, quanto a sua representatividade, no capítulo seguinte.

\title{
ANÁLISE DOS RESULTADOS
}

\section{A Licitação Sustentável Não Ofende o Princípio do Julgamento Objetivo}

A luz do caput do artigo $3^{\circ}$ da Lei $n^{0} 8.666 / 93$, a proposta mais vantajosa é aquela que consegue reunir a melhor qualidade possivel ao menor preço. No entanto, a Administração Pública, além do preço leva em conta outros fatores, como a durabilidade do produto, a qualidade, melhor técnica, maior potencialidade financeira do licitante ou mesmo, a apresentação do produto a ser comprado.

A proposta vencedora será aquela que atender as especificações da Administração Pública descritas no edital e cumulativamente apresentar o menor preço.

Tal fato pode levar a concluir que o menor preço é condição necessária, porém não é condição por si só suficiente para que uma proposta se logre vencedora.

Então, uma vez que os padrões ambientais são interessantes ao Estado e constituem um processo fundamental para se alcançar a eco eficiência, eles precisam estar inseridos e descritos de forma clara e específica nos editais, para que se evite qualquer tipo de dúvida, afastando a subjetividade nos processos licitatórios. Dessa forma, a licitação sustentável não violará o julgamento objetivo das propostas, pois os padrões dos certames estarão descritos nos editais. (Bim, 2011).

Corroborando com o entendimento descrito, transcreve-se a Súmula $n^{0} 177$ do Tribunal de Contas da União:

\begin{abstract}
A definição precisa e suficiente do objeto licitado constitui regra indispensável da competição, até mesmo como pressuposto do postulado de igualdade entre os licitantes, do qual é subsidiário o princípio da publicidade, que envolve o conhecimento, pelos concorrentes potenciais das condições básicas da licitação, constituído, na hipótese particular da licitação para compra, a quantidade demandada uma das especificações mínimas e essenciais à definição do objeto do pregão.
\end{abstract}

Uma vez que os interesses da Administração constem previamente do edital de forma precisa e motivada, não gerará óbice legal às licitações sustentáveis.

Conforme Valente (2011), no que se refere à realização de licitações, a Constituição Federal estabelece que exista igualdade de condições a todos os concorrentes e veda a existência de exigências que venham comprometer o caráter isonômico da licitação. 


\section{Análise dos Relatórios de Gestão de 2012 Referentes à Gestão Ambiental e às Licitações Sustentáveis}

A Portaria TCU $n^{0}$ 150/2012 e a Decisão Normativa - TCU nº 119/2012 em conjunto com as orientações dos órgãos de controle interno de cada Unidade Jurisdicional dispuseram normatização quanto ao preenchimento do Anexo 9 do Relatório de Gestão referente ao exercício de 2012 que, os Tribunais estão obrigados a apresentar nos termos do artigo 70 da Constituição Federal, no tocante à gestão ambiental e às licitações sustentáveis.

As Unidades Jurisdicionadas consideradas neste estudo foram os 24 Tribunais Regionais do Trabalho.

O item 9 recebe o título de Gestão do uso de recursos renováveis e sustentabilidade ambiental e está subdividido no quadro A do subitem 9.1, denominado de Gestão ambiental e licitações sustentáveis.

O anexo é composto por treze afirmações a respeito de aspectos que analisam a gestão ambiental no âmbito de várias unidades jurisdicionais no caso em estudo, analisam-se os relatórios apresentados pelos vinte e quatro Tribunais Regionais do Trabalho, e as questões foram respondidas pelos gestores responsáveis das respectivas áreas solicitadas.

Os gestores assinalaram os campos de acordo com o nível de concordância à afirmação dada, para isso, levou-se em conta, uma escala avaliativa que variou de 1 a 5 , representando as seguintes considerações:

(1) Totalmente inválida: significa que o fundamento descrito na afirmativa é integralmente não aplicado no contexto da UJ.

(2) Parcialmente inválida: significa que o fundamento descrito na afirmativa é parcialmente aplicado no contexto da UJ, porém, em sua minoria.

(3) Neutra: significa que não há como afirmar a proporção de aplicação do fundamento descrito na afirmativa no contexto da UJ.

(4) Parcialmente válida: significa que o fundamento descrito na afirmativa é parcialmente aplicado no contexto da UJ, porém, em sua maioria.

(5) Totalmente válida: significa que o fundamento descrito na afirmativa é integralmente aplicado no contexto da UJ.

Os relatórios de gestão estão disponiveis no site do Tribunal de Contas da União e a sua apresentação é obrigatória no primeiro semestre do ano, a fim de que sejam direcionadas ações que fomentem a gestão ambiental e promovam a implementação das licitações sustentáveis no âmbito da Administração Pública federal com vistas ao atendimento dos princípios constitucionais e normativos legais.

TABELA1 - RELATÓRIO DE GESTÃO DE 2012 - TRIBUNAIS REGIONAIS DO TRABALHO

\begin{tabular}{|c|c|c|c|c|c|c|}
\hline Aspectos sobre a gestão ambiental & 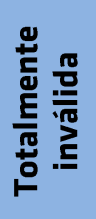 & 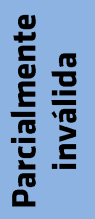 & 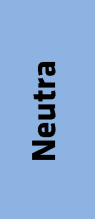 & 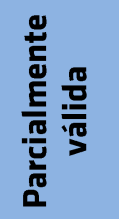 & 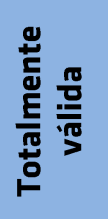 & 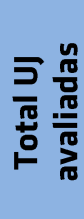 \\
\hline $\begin{array}{c}\text { A UJ tem incluído critérios de sustentabilidade ambiental em } \\
\text { suas licitações que levem em consideração os processos de } \\
\text { extração ou fabricação, utilização e descarte dos produtos e } \\
\text { matérias primas. }\end{array}$ & $0 \%$ & $25 \%$ & $20 \%$ & $37,5 \%$ & $17,5 \%$ & 24 \\
\hline
\end{tabular}

OS, Organizações e Sustentabilidade, 7(2), p. 99-113, Londrina, PR, jul./dez. 2019.

ISSN 2318-9223, http://www.uel.br/revistas/uel/index.php/ros/issue/view/1607/showToc 


\begin{tabular}{|c|c|c|c|c|c|c|}
\hline $\begin{array}{c}\text { Em uma análise das aquisições dos últimos cinco anos, os } \\
\text { produtos atualmente adquiridos pela unidade são produzidos } \\
\text { com menor consumo de matéria-prima e maior quantidade de } \\
\text { conteúdo reciclável. }\end{array}$ & $0 \%$ & $33 \%$ & $33 \%$ & $25 \%$ & $9 \%$ & 24 \\
\hline $\begin{array}{c}\text { A aquisição de produtos pela unidade é feita dando-se } \\
\text { preferência àqueles fabricados por fonte não poluidora bem } \\
\text { como por materiais que não prejudicam a natureza (ex. produtos } \\
\text { de limpeza biodegradáveis). }\end{array}$ & $8,5 \%$ & $29 \%$ & $21 \%$ & $12,5 \%$ & $29 \%$ & 24 \\
\hline $\begin{array}{c}\text { Nos procedimentos licitatórios realizados pela unidade, tem sido } \\
\text { considerada a existência de certificação ambiental por parte das } \\
\text { empresas participantes e produtoras (ex: ISO), como critério } \\
\text { avaliativo ou mesmo condição na aquisição de produtos e } \\
\text { serviços. }\end{array}$ & $25 \%$ & $21 \%$ & $4 \%$ & $33 \%$ & $17 \%$ & 24 \\
\hline $\begin{array}{c}\text { No último exercício, a unidade adquiriu bens/produtos que } \\
\text { colaboram para menor consumo de energia (ex: torneiras } \\
\text { automáticas, lâmpadas econômicas). }\end{array}$ & $4 \%$ & $12,5 \%$ & $0 \%$ & $37,5 \%$ & $46 \%$ & 24 \\
\hline $\begin{array}{l}\text { No último exercício, a unidade adquiriu bens/produtos reciclados } \\
\text { (ex: papel reciclado). }\end{array}$ & $12,5 \%$ & $0 \%$ & $12,5 \%$ & $12,5 \%$ & $46 \%$ & $23^{*}$ \\
\hline $\begin{array}{l}\text { No último exercício, a instituição adquiriu veículos automotores } \\
\text { mais eficientes e menos poluentes ou que utilizam combustiveis } \\
\text { alternativos. }\end{array}$ & $8 \%$ & $4 \% 0$ & $17 \%$ & $17 \% 6$ & $46 \%$ & $22^{* *}$ \\
\hline $\begin{array}{c}\text { Existe uma preferência pela aquisição de bens/produtos } \\
\text { passiveis de reutilização, reciclagem ou reabastecimento (refil } \\
\text { e/ou recarga) }\end{array}$ & $33 \%$ & $17 \%$ & $25 \%$ & $12,5 \%$ & $12,5 \%$ & 24 \\
\hline $\begin{array}{l}\text { Para a aquisição de bens e produtos são levados em conta os } \\
\text { aspectos de durabilidade e qualidade de tais bens e produtos. }\end{array}$ & $0 \%$ & $4 \%$ & $8 \%$ & $25 \%$ & $63 \%$ & 24 \\
\hline $\begin{array}{l}\text { Os projetos básicos ou executivos, na contratação de obras e } \\
\text { serviços de engenharia, possuem exigências que levem à } \\
\text { economia da manutenção e operacionalização da edificação, à } \\
\text { redução do consumo de energia e água e à utilização de } \\
\text { tecnologias e materiais que reduzam o impacto ambiental. }\end{array}$ & $0 \%$ & $4 \%$ & $8 \%$ & $46 \%$ & $42 \%$ & 24 \\
\hline $\begin{array}{c}\text { Na unidade ocorre separação dos resíduos recicláveis } \\
\text { descartados, bem como sua destinação, como referido no } \\
\text { Decreto } n^{0} 5.940 / 2006 \text {. }\end{array}$ & $0 \%$ & $0 \%$ & $12,5 \%$ & $54 \%$ & $\begin{array}{l}33,5 \\
\%\end{array}$ & 24 \\
\hline $\begin{array}{c}\text { Nos últimos exercícios, a UJ promoveu campanhas entre os } \\
\text { servidores visando a diminuir o consumo de água e energia } \\
\text { elétrica. }\end{array}$ & $8 \%$ & $4 \%$ & $4 \%$ & $12.5 \%$ & $71,5 \%$ & 24 \\
\hline $\begin{array}{l}\text { Nos últimos exercícios, a UJ promoveu campanhas de } \\
\text { conscientização da necessidade de proteção do meio ambiente e } \\
\text { preservação de recursos naturais voltadas para os seus } \\
\text { servidores. }\end{array}$ & $4 \%$ & $4 \%$ & $0 \%$ & $21 \%$ & $71 \%$ & 24 \\
\hline
\end{tabular}

$$
\begin{aligned}
& \text { Fonte: Tribunal de Contas da União } \\
& \text { *TRT 7 }{ }^{a} \text { não respondeu a questão número } 6 \\
& \text { * TRT } 7^{\text {a }} \text { e TRT } 12^{a} \text { não responderam a questão número } 7
\end{aligned}
$$

A tabela 1 foi baseada no Quadro A.9.1 referente ao anexo 9 do Relatório de Gestão - 2012 do TCU, o resultado das assertivas foram transformados em percentuais a fim de melhor visualização dos dados a serem analisados.

OS, Organizações e Sustentabilidade, 7(2), p. 99-113, Londrina, PR, jul./dez. 2019. 
Depreende-se que, $17,5 \%$ das instituições analisadas inserem totalmente os critérios de sustentabilidade em seus processos licitatórios contra $25 \%$ em que a afirmativa é parcialmente inválida, 20\% é neutra e a maioria classificou-se como parcialmente válida. Pode-se verificar, portanto, que a inclusão de critérios de sustentabilidade nas licitações carece de maior implementação em grande parte das instituições analisadas.

Outra questão que deixou a desejar um maior empenho entre os Tribunais foi a respeito da afirmação quanto à preferência pela aquisição de bens e produtos reutilizáveis, recicláveis ou com recarga, onde a maioria das instituições não demonstrou preocupação com o quesito.

Constatou-se que 33\% dos tribunais não dão preferência em adquirir produtos reutilizáveis ou recicláveis e apenas $12,5 \%$ das entidades importam-se em incluir o referido critério às suas compras de bens e produtos.

Quanto à assertiva que questionou a preferência por adquirir produtos fabricados por fonte não poluidora e por materiais que não prejudicam a natureza, observa-se que o resultado foi um surpreendente empate entre os critérios parcialmente inválido e totalmente válido, ou seja, 29\% das instituições cumpriram parcialmente o critério adquirindo às vezes produtos biodegradáveis ou demonstraram preocupação total em estabelecer o critério rígido na aquisição de produtos não poluentes. Esta constatação demonstrou ser necessário um maior envolvimento dos tribunais quando se trata de comprar produtos que agridam menos o meio ambiente.

Victor (2015) recomenda que os governos formulem e implantem uma política de aquisições que reconheça a importância da sustentabilidade e que induza modelos padrões e de ampla adesão que possam gerar maior consciência de sustentabilidade aos órgãos que realizam compras públicas.

Importa realçar que as últimas assertivas obtiveram maior pontuação no quesito totalmente válida, as mesmas ponderam sobre as promoções de campanhas entre os servidores com intuito de diminuir o consumo de água e energia elétrica e sobre a conscientização dos servidores da necessidade de proteger o meio ambiente e preservar os recursos naturais.

Por meio das compras públicas, o governo tem o poder de promover um enorme estímulo para atividades inovadoras. Na Europa, os contratos públicos têm estado no centro das recentes discussões sobre a inovação política a respeito de contratações sustentáveis (Brammer, 2011).

Para finalizar a discussão, importante salientar que com os dados obtidos nota-se a necessidade de implementar esforços para promover de modo efetivo as licitações sustentáveis nos Tribunais, fomentando ações que agreguem medidas para melhorar a gestão ambiental e atendam com eficácia aos dispositivos legais.

\section{CONCLUSÕES}

Da análise dos resultados obtidos através da tabela 1 pode ser observado que grande parte das Unidades Jurisdicionais analisadas auto avaliaram-se distante da escala 5, ou seja, não aplicam plenamente os critérios de sustentabilidade ambiental nas especificações de bens e serviços contratados.

A utilização dos critérios "verdes" nas contratações de bens, obras e serviços pelo Poder Público gerou certas controvérsias legais, como a possivel frustração do princípio da competitividade entre os licitantes ou eventual quebra de economicidade, visto que para atender aos critérios sustentáveis os serviços e produtos apresentam um custo mais elevado.

É prudente considerar que o caput do art. $3^{\circ}$ da Lei $n^{0} 8.666 / 93$ ao referir-se à seleção da proposta mais vantajosa não quis dizer necessariamente em adquirir produtos ou serviços sem qualidade,

OS, Organizações e Sustentabilidade, 7(2), p. 99-113, Londrina, PR, jul./dez. 2019.

ISSN 2318-9223, http://www.uel.br/revistas/uel/index.php/ros/issue/view/1607/showToc 
mais sim produtos que agreguem maior benefício para a coletividade compensando o valor pago através da geração de economia a longo prazo.

Tampouco o caráter competitivo da licitação foi relegado, uma vez que o conjunto normativo apresentado nesta pesquisa demonstrou a legitimidade em guiar a escolha dos bens e serviços contratados na adoção de critérios sustentáveis, visando assim atender plenamente aos princípios constitucionais, ou seja, acatar a supremacia do interesse público sobre o particular.

Observou-se ainda durante a execução do trabalho haver poucas pesquisas acadêmicas sobre as licitações "verdes" ou sustentabilidade, tal fato demonstra que o ambiente é fértil para pesquisas e lançamentos de ideias que propiciem aos órgãos públicos um melhor aproveitamento dos recursos naturais do Planeta, objetivando a implantação de políticas capazes de incorporar nas organizações públicas práticas eficientes, racionais e permanentes de compras e contratações sustentáveis.

Diante do exposto, observa-se que as ferramentas necessárias à consolidação das licitações sustentáveis estão disponiveis no ordenamento jurídico, no entanto, pode levar algum tempo para que o mercado de fornecedores de bens e serviços ao Poder Público molde-se aos critérios de sustentabilidade esperados. Esta pesquisa limitou-se ao exercício de 2012 e cabe sugerir, como pesquisas futuras, verificar como as compras sustentáveis são abordadas em outras esferas do Poder Público nacional e até mesmo em outros países, visto que a sustentabilidade é um assunto globalizado e de interesse coletivo.

\section{REFERÊNCIAS}

Barki, T. V. P. (2011) Direito Internacional Ambiental como fundamento jurídico para licitações sustentáveis no Brasil. In: Santos, M. G. \& Barki, T. V. P. (Coord.). Licitações e contratações públicas sustentáveis. Belo Horizonte: Fórum.

Bertogna, V. (2011) Princípios constitucionais ambientais aplicáveis às licitações sustentáveis. In: Santos, M G. \&; Barki, T. V. P. (Coord.). Licitações e contratações públicas sustentáveis. Belo Horizonte: Fórum.

Betiol, L. S., Uehara, T. H. K., Laloe, F. K., Appugliese, G. A., Adeodato, S., Ramos, L., Monzoni Neto, M. P. (2012) Compra Sustentável- A força do consumo público e empresarial para uma economia verde inclusiva. São Paulo: Programa de gestão pública e cidadania. Escola de administração de da Fundação Getúlio Vargas.

Bim, E. F. (2011) Considerações sobre a juridicidade e os limites da licitação sustentável. In: Santos, M. G. \& Barki, T. V. P., (Coord.). Licitações e contratações públicas sustentáveis. Belo Horizonte: Fórum.

Bliacheris, M. W. (2011) Licitações Sustentáveis: política pública. In: Santos, M. G. \& Barki, T. V. P. (Coord.). Licitações e contratações públicas sustentáveis. Belo Horizonte: Fórum, 2011.

Brammer, S. \& Walker, H. (2011). Sustainable procurement in the public sector: an international Comparative study. International Journal of Operations \& Production Management, 31(4), p. 452-476

Brasil. (1981). Lei $n^{0}$ 6.938, de 31 de agosto de 1981. Dispõe sobre a política nacional do meio ambiente. Recuperado de http://www.planalto.gov.br/ccivil_03/lei/l6938.htm.

(1998). Constituição da República Federativa do Brasil de 1988, de 05 de outubro de 1988. Recuperado de http://www.planalto.gov.br/ccivil._03/constituição.

(1993). Lei nº 8.666 - das licitações e contratos da administração pública, de 21 de junho de 1993. Recuperado de http://www.planalto.gov.br/ccivil._03//8666con.htm.

OS, Organizações e Sustentabilidade, 7(2), p. 99-113, Londrina, PR, jul./dez. 2019.

ISSN 2318-9223, http://www.uel.br/revistas/uel/index.php/ros/issue/view/1607/showToc 
(2001). Lei $n^{0}$ 10.257, de 10 de julho de 2001. Regulamenta os artigos 182 e 183 da Constituição Federal, estabelece diretrizes gerais da política urbana. Recuperado de http://www.planalto.gov.br/ccivil_03/leis/leis_2001/110257.htm.

(2009). Lei $n^{0}$ 12.187, de 29 de dezembro de 2009. Institui a política nacional sobre a mudança do clima - PNMC. Recuperado de http://www.planalto.gov.br/ccivil_03/ato20072010/2009/lei/l12187.htm.

(2010a). Lei $n^{0}$ 12.305, de 02 de agosto de 2010. Institui a política nacional de resíduos sólidos. Recuperado de: http://www.planalto.gov.br/ccivil_03/ato2007-2010/2010/lei//12305.htm.

(2010b). Lei $n^{0}$ 12.349, de 15 de dezembro de 2010. Altera as Leis nos 8.666, de 21 de junho de 1993, 8.958, de 20 de dezembro de 1994, e 10.973, de 2 de dezembro de 2004; e revoga o \j 10 do art. 20 da Lei no 11.273, de 6 de fevereiro de 2006. Recuperado de https://www.planalto.gov.br/ccivil_03/_ato2007-2010/2010/lei/I12349.htm.

(2011). Lei $n^{0}$ 12.462, de 04 de agosto de 2011. Institui o regime diferenciado de contratações públicas. Recuperado de http://www.planalto.gov.br/ccivil_03/ato20112014/2011/Lei/L12462.htm.

Conselho Nacional de Justiça. (2007). Recomendação 11 de 22/5/2007. Recuperado de http://www.cnj.jus.br/atos-normativos?documento=867.

Conselho Superior da Justiça do Trabalho. (n.d.). Acordos de cooperação técnica CSJT. Recuperado de http://www.csjt.jus.br/acordos-de-coop.-tecnica.

(2011). Acordo de Cooperação Técnica $n^{0}$ 01/2011. Recuperado de http://www.csjt.jus.br/c/document_library/get_file?uuid=d235c84d-3264-45bc-b609-

5f4f95dedbe3\&groupld=955023.

plenario.

(2012). Resolução 103 de 28/05/2012.Recuperado de http://www.csjt.jus.br/atos-do-

Costa, C. F., Diniz, M. F. S., Cunha, N. R. S. \& Pires, R. R. (2016) O Fator Sustentabilidade nas Licitações e Contratações Públicas. Revista REUNA, 21(4), p. 37-56. Belo Horizonte: Reuna.

Ferreira, M. A. S. O. (2011) As licitações públicas e as novas leis de mudança climática e de resíduos sólidos. In: Santos, M. G. \& Barki, T. V. P. (Coord.). Licitações e contratações públicas sustentáveis. Belo Horizonte: Fórum.

Governos locais pela sustentabilidade - ICLEI. (2007). Compras sustentáveis pela inovação e por uma economia verde e inclusiva. Recuperado de http://archive.iclei.org/index.php?id=13341.

Machado, P. A. L. (2011) Direito ambiental brasileiro. 19. ed. São Paulo: Malheiros.

Martins, G. A., \& Theóphilo, C. R. (2009) Metodologia da Investigação Cientifica para Ciências Sociais Aplicadas. 2. ed. São Paulo: Atlas.

Meirelles, H. L. (2003). Direito administrativo brasileiro.28. ed. São Paulo: Malheiros.

Meneguzzi, R. M. (2011) Conceito de licitação sustentável. In: Santos, M. G \& Barki, T. V. P. (Coord.). Licitações e contratações públicas sustentáveis. Belo Horizonte: Fórum.

Ministério do Meio Ambiente. (n.d.). Agenda 21. Recuperado de http://www.mma.gov.br/responsabilidade-socioambiental/agenda-21.

(2009). Agenda ambiental na administração pública - A3P. Recuperado dehttp://www.mma.gov.br/estruturas/a3p/_arquivos/cartilha_a3p_36.pdf. 
http://www.mma.gov.br/responsabilidade-socioambiental/a3p.

Ministério do Planejamento. (2010a). Instrução Normativa nº 01, de 01 de janeiro de 2010. Dispõe sobre os critérios de sustentabilidade ambiental na aquisição de bens, contratação de serviços ou obras pela administração pública federal direta, autárquica e fundacional. Recuperado de http://cpsustetaveis.planejamento.gov.br/?page_id=21.

(2010b). Guia de compras sustentáveis para administração federal. Recuperado de http://cpsustentaveis.planejamento.gov.br//2013/08.

Organização das Nações Unidas (ONU) (1987). Relatório de Brutdland - Nosso futuro comum. Recuperado de http://www.onu.org.br/a-onu-em-acao/a-onu-e-o-meio-ambiente.

Sampieri, R. H, Collado, C. F. \& Lucio, P. B. (2006) Metodologia de pesquisa. 3. ed. São Paulo: Mc Graw Hill.

Tribunal de Contas da União (TCU). (n.d.). Súmula $n^{\circ} 177$ do Tribunal de Contas da União. Recuperado de

http://portal2.tcu.gov.br/portal/page/portal/TCU/jurisprudencia/sumulas/BTCU_ESPECIAL_06_D E_04_12_2007_SUMULAS.pdf. 